\title{
JOGO DE LINGUAGEM E FORMAÇÃO HUMANA: O PAPEL DO ACASO SOB UMA ABORDAGEM WITTGENSTENIANA*
}

\author{
Cristiane M. C. Gottschalk \\ (...) as coisas que ocorrem corretamente por obra de um \\ acaso não ocorrem pelo guiar humano. \\ Platão (Mênon 99) \\ A imprevisibilidade do comportamento bumano. Se não \\ fosse isto - diríamos ainda que nunca se pode saber o que se passa \\ com qualquer outra pessoa?
}

Ludwig Wittgenstein $\left(Z \int 603\right) 1$

Quem diria que as manchas vivem e ajudam a viver? Tinta, sangue, cheiro (...) O que eu faria sem o absurdo e o fugaz? 2

Frida Kahlo

\begin{abstract}
Resumo
Neste texto, recorro a alguns conceitos forjados por Wittgenstein na segunda fase de sua investigação filosófica, com o objetivo de refletir sobre o papel do acaso na constituição de novos saberes nas ciências empíricas e, de modo mais geral, como o imprevisível que nos assola intervém na formação humana. Parto do pressuposto de que organizamos nosso mundo exterior e interior através do que Wittgenstein denomina de "jogos de linguagem", a saber, sistemas de referência que intermediam as relações entre pensamento (mundo interior) e fatos empíricos (mundo exterior). Ao longo deste processo, são constituídas relações de sentido (regras que aprendemos a seguir), que garantem uma margem de (im)previsibilidade ao nosso comportamento, ao mesmo tempo em que se tornam as condições de possibilidade para que haja conhecimento. Concluo apontando para a relevância do acaso não apenas para a ampliação de novos saberes e descobertas nas ciências em geral, mas sobretudo, como condição para uma formação humana crítica e não dogmática.
\end{abstract}

Palavras-chave: Wittgenstein, jogo de linguagem, acaso e formação humana.

Como observa o filósofo Ludwig Wittgenstein na epígrafe acima, o comportamento humano é imprevisivel. Caso contrário, não diríamos que nunca se pode

\footnotetext{
* DOI - 10.29388/978-65-86678-51-2-0-f.537-550

${ }^{1}$ Utilizarei doravante as seguintes siglas para me referir à obra de Wittgenstein: Z (Zettel), IF (Investigações Filosóficas) e DC (Da Certera).

${ }^{2}$ In: Percy, Allan. Frida Kahlo para inconformistas. Rio de Janeiro: Sextante, 2020, p.22.
} 
saber o que se passa no interior do outro, que nossas sensações e pensamentos são privados, e assim por diante. No entanto, apesar desta interioridade indevassável, como se explica, então, a possibilidade da comunicação de sentidos compartilhados por nós, em meio ao acaso e imprevisibilidade dos comportamentos humanos e fatos mundanos? Argumentarei que esta imprevisibilidade, tanto interna como externa, que, por vezes, nos atemoriza, mas que também nos fascina, é o que nos torna humanos. E que, paradoxalmente, são as regras que aprendemos a seguir, imersas em nossas formas de vida, a condição para atribuirmos sentido ao acaso, ou às "manchas" que nos rodeiam e que nos ajudam a viver, como expressa a artista Frida Kahlo na epígrafe seguinte.

De fato, se agíssemos de modo totalmente previsível, poderíamos ser facilmente substituídos por máquinas. Não haveria criação, pensamento crítico, originalidade ou qualquer outro conceito que pressupõe o novo, a mudança e o sentimento de estar vivo. Só faz sentido falar em algo imprevisível em contraposição ao que se espera acontecer, se for possível perceber alguma regularidade em meio ao caos. Daí que o conceito de regra passa a adquirir uma importância fundamental na filosofia de Wittgenstein, que tinha como um de seus principais objetivos esclarecer as relações entre pensamento, linguagem e mundo, a partir das seguintes questões: Como é possível que através de sons empíricos sejamos capazes de atribuir sentido ao que sentimos e observamos? Quais são as condições para a comunicação e constituição destes sentidos linguísticos?

Ao longo de sua investigação filosófica, Wittgenstein responderá as questões acima observando que organizamos nosso mundo exterior e interior através do que será denominado por ele de "jogos de linguagem", a saber, sistemas de referência que intermediam as relações entre pensamento (mundo interior) e fatos empíricos (mundo exterior). Segundo ele, a linguagem não se reduz a uma função meramente descritiva ou comunicativa, mas sobretudo, produr sentidos, apropriando-se de fragmentos do empírico (como as manchas de Kahlo) que ao serem conectadas com determinados sons linguísticos estabelecem relações de sentido (regras que aprendemos a seguir), as quais, por sua vez, tornar-se-ão condição para a possibilidade de conhecimento. Desta perspectiva pragmática da linguagem, argumento a seguir que as regras aprendidas, embora comportem um certo grau de necessidade, permitem uma margem de (im)previsibilidade ao nosso comportamento humano, o que possibilita também vermos novos aspectos no que nos parece, em um primeiro momento, absurdo e fugaz. Afinal, agir regularmente, como veremos, é diferente de agir uniformemente.

\section{O conceito de "jogo de linguagem" em Wittgenstein}

O termo "jogo de linguagem" é um conceito basilar na obra do segundo Wittgenstein, por vezes, confundido com um sistema fechado de regras que determinaria o significado de um conceito (aproximando-o do estruturalismo de Saussure) ou como um sistema de interpretantes (tal como postulado por Peirce). Pelo contrário, nosso filósofo irá mostrar através de sua terapia filosófica ${ }^{3}$, que nossos jogos de linguagem constituem

\footnotetext{
3 Wittgenstein inspirou-se na terapia freudiana para denominar seu método de investigação de "terapia filosófica", na medida em que seu "método" não tem como finalidade a elaboração de teses filosóficas, mas apenas a dissolução de confusões de natureza conceitual a partir de um diálogo polifônico, onde seus interlocutores representam posições filosóficas as mais diversas, tais como: o logicismo, o mentalismo, o behaviorismo, o pragmatismo etc.
} 
um sistema aberto de regras, cuja significação se dá a partir de um agir comum, fundamentadas, assim, em hábitos e instituições pertencentes a nossas formas de vida ${ }^{4}$. Aprendemos a seguir as regras tacitamente, ou através de um treino, e neste sentido, não se segue regras privadamente, trata-se de um agir coletivo ${ }^{5}$. Além do que, Wittgenstein observa que nos jogos de linguagem do cotidiano, as regras em geral são intrinsecamente vagas, o que nos permite transitar de um jogo a outro.

Embora Wittgenstein ao longo de toda a sua obra não tenha definido o que entende por jogo de linguagem, desde o início de IF ele nos oferece inúmeros exemplos de jogos de linguagem, como por exemplo, desde os jogos de linguagem referenciais recorrentes nas ciências (formular uma hipótese e examiná-la, descrever um objeto pela aparência ou pelas suas medidas, relatar um acontecimento, fazer suposições sobre o acontecimento...) até jogos que não têm uma função referencial, tais como, adivinhar enigmas, contar piadas, resolver uma tarefa de cálculo aplicado, traduzir de uma língua para outra, cumprimentar, rezar, agradecer, etc. (IF \$23). Todos estes jogos envolvem não apenas palavras e expressões linguísticas, mas também interlocutores, ações, objetos empíricos, sensações e técnicas diversas que, gradualmente, passam a se conectar e a constituir regras que aprendemos a seguir. Assim, a linguagem passa a ser vista por Wittgenstein como um conjunto aberto de jogos de linguagem, no interior dos quais nos expressamos e nos comunicamos, e sobretudo, produzimos novos sentidos.

O jogo de xadrez é utilizado de forma recorrente por Wittgenstein, como metáfora do funcionamento das palavras em nossa linguagem. Cada peça deste jogo é movimentada seguindo-se uma determinada regra. O peão movimenta-se verticalmente, uma casa a cada jogada. Já o cavalo, desloca-se em "L". O bispo em diagonal, e assim por diante. Analogamente, empregamos as palavras como as peças de um jogo, seguindo suas respectivas regras. A mesma palavra em outro jogo de linguagem seguirá outras regras, e compreender esta palavra é ser capaz de seguir a regra como se espera pela comunidade que compartilha a mesma gramática ${ }^{6}$ dos usos das palavras, a saber, o conjunto de regras que seguimos ao proferirmos nossas expressões linguísticas. A palavra "rei" terá um sentido diferente se aparecer em um livro de história. E ainda outro sentido se dissermos em tom jocoso, "ele estava se sentindo o rei da cocada!", e muitos outros sentidos que podemos imaginar para o emprego desta mesma palavra. Ao empregarmos uma palavra qualquer de nossa linguagem, seu sentido dependerá do contexto em que está sendo aplicada, ou em uma terminologia wittgensteiniana, do jogo de linguagem em que a palavra está sendo aplicada. Assim, em função do contexto de aplicação da palavra escolhemos seguir uma ou outra regra de jogos de linguagem distintos (a palavra "rei" no jogo de linguagem do xadrez, a palavra "rei" nos jogos de linguagem da história, ou utilizada de modo pejorativo).

\footnotetext{
${ }^{4} \mathrm{O}$ termo "formas de vida" é utilizado por Wittgenstein poucas vezes ao longo de sua obra, mas tem uma importância crucial em sua crítica à metafísica, ao ressaltar a natureza convencional dos fundamentos da significação linguística, a saber: são fundamentos sem fundamentos, na medida em que abarcam nossos hábitos e instituições, nas mais diversas culturas, em contínua transformação.

${ }^{5}$ Segundo Wittgenstein, seguir uma regra não é o mesmo que interpretá-la. A interpretação de uma regra pode ser vista como apenas outra formulação simbólica da regra, enquanto que o significado da regra se manifesta na sua aplicação pública, e não privada. Aprende-se uma regra a partir de exemplos, em diferentes tipos de lições. Há lições que

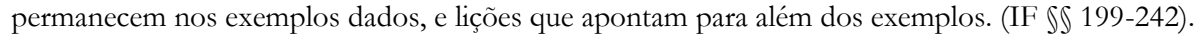

${ }^{6} \mathrm{O}$ termo "gramática" é utilizado por Wittgenstein em um sentido diferente da gramática de uma língua, com suas regras de sintaxe. Trata-se, aqui, da gramática de usos de um conceito, cujo significado vai sendo constituído gradualmente, a partir das diversas aplicações da palavra que expressa o conceito em questão.
} 
Aprendemos a transitar de um jogo para outro, ampliando-se, assim, os sentidos que atribuímos a nossas palavras e expressões linguísticas.

Entretanto, a metáfora do jogo de xadrez tem seus limites. Pode induzir o leitor de Wittgenstein a acreditar que somos determinados pelas regras de nossos jogos de linguagem, mesmo que sejam de natureza convencional e arbitrária. Na verdade, na maior parte das vezes as regras que seguimos não determinam nossa ação, nem mesmo no contexto de um jogo de xadrez, no qual suas regras apenas delimitam o campo de ação dos jogadores, que movimentam as peças conforme as suas regras, e não determinados por elas. A cada nova jogada cada um dos jogadores levará em consideração o lance de seu adversário, na maior parte das vezes, imprevisivel. É neste sentido que, de modo geral, agimos no interior de jogos de linguagem de modo regular, e não uniforme.

Você deve ter em atenção que o jogo de linguagem é, por assim dizer, imprevisível. Quero dizer: não se baseia em fundamentos. Não é razoável (ou irrazoável), Está aí - tal como a nossa vida. (Wittgenstein, DC §559)

E o conceito de saber está associado ao do jogo de linguagem. (Wittgenstein, DC $\$ 560)$

Como a nossa vida, os jogos de linguagem também são dinâmicos e imprevisíveis. Não se tratam, portanto, de sistemas ancorados em algum tipo de racionalidade prévia, como se houvesse fundamentos últimos pré-existentes a eles; pelo contrário, suas regras são vagas o suficiente, expressando nossas formas de vida bumanas, a saber, nossos hábitos culturais, nossas convenções e instituições, em contínua transformação. Mesmo no interior de um mesmo jogo de linguagem, podemos imaginar situações em que suas regras podem se modificar ao longo do jogo:

Não é elucidativa a analogia da linguagem com o jogo? Podemos muito bem imaginar pessoas que se divertem num campo, jogando com uma bola, de sorte que começassem diversos jogos conhecidos, não levassem alguns até o fim, entrementes atirassem a bola para o alto sem objetivo, corressem uns atrás dos outros com a bola por brincadeira e atirassem-na uns nos outros, etc. E agora alguém diz: As pessoas jogam o tempo todo um jogo de bola, e por isso guiam-se, a cada jogada, por regras determinadas.

E não há também o caso, onde jogamos e - 'make up the rules as we go along'? Sim, também o caso, em que nós as modificamos - as we go along. (IF, \$83)

Como se vê no exemplo acima, o acaso pode adquirir um papel fundamental na configuração de um jogo de linguagem, desde os mais simples, como o da nomeação, até os mais complexos, como os jogos das ciências em seus mais diversos níveis de especialização. Suas regras podem se alterar conforme formos jogando, e consequentemente, determinados conceitos e expressões linguísticas passam a adquirir novos significados. Segundo Moreno (1995), é exatamente esta multiplicidade imprevisivel de usos da linguagem que possibilita a constituição de novos sentidos. Daí que os jogos de 
linguagem não se apoiam em fundamentos últimos; ou se quisermos falar em fundamentos, estes são de natureza convencional, justificativas para as nossas ações, e não causas? .

Entretanto, se o jogo de linguagem não se baseia em fundamentos últimos, não estaríamos diante de um paradoxo? Como afirmar que sabemos algo e como verificar a validade do que afirmamos em contextos instáveis, imprevisíveis, como parecem ser os jogos de linguagem? Argumentaremos que não há contradição aqui, pelo contrário, é exatamente a imprevisibilidade de nossas formas de vida (expressas linguisticamente por meio de jogos de linguagem), o que possibilita a descoberta de novos saberes, e que o acaso é parte fundante deste processo dinâmico que instaura e/ou transforma jogos de linguagem, cujas regras se tornam, gradativamente, condições de sentido de nossos enunciados cotidianos $e$ científicos.

Ao invés de apresentar teses sobre o acaso, seguindo a inspiração terapêutica e metodológica de Wittgenstein iniciarei com dois exemplos na história da medicina, que podem jogar luz sobre a riqueza do acaso não apenas para a constituição de novos saberes, como também, por se tratar de um elemento vital nas demais esferas da formação do ser humano.

\section{$\mathrm{O}$ acaso nos jogos de linguagem das ciências}

$\mathrm{Na}$ medicina encontramos casos emblemáticos em que o acaso desempenha um papel crucial na descoberta de novos conhecimentos. É conhecida a história trágica do médico húngaro Ignaz Phillip Semmelweis (1818-1865) ${ }^{8}$, que descobriu não só as causas da febre puerperal, doença gravíssima que matava grande parte das parturientes atendidas nos hospitais de sua época, como também o modo de a prevenir. Intrigado com o fato de que as mulheres que tinham parto em casa raramente padeciam desta doença mortal, e o acaso de ter acompanhado o sofrimento de um colega no hospital com os mesmos sintomas da febre puerperal, levaram-no à convicção de que se tratava de um processo infeccioso, e que bastaria a simples higiene das mãos dos médicos, estudantes e parteiras para que a doença fosse evitada. No entanto, esta hipótese foi imediatamente vista como ingênua e descabida, e mesmo com a publicação de seu livro, A etiologia, o conceito e a profilaxia da febre puerperal, publicado em 1861, a resistência de seus colegas para aceitar sua descoberta só aumentou, a ponto de ter sido expulso de Viena em 1849, e terminado seus dias em um asilo para doentes mentais, onde faleceu em 1865 por infecção em ferimento na mão.

Outro caso paradigmático na área médica, em que o acaso propiciou outra grande descoberta, foi a descoberta do transmissor do tifo exantemático: o piolho. Durante a epidemia de tifo na região de Tunis, em 1909, o médico Charles Nicolle e outros colegas seus que trabalhavam em um hospital superlotado de tifosos constataram que esta doença não era transmitida para os demais doentes que também estavam internados. Segundo Azanha:

\footnotetext{
${ }^{7}$ Esta oposição é fundamental para a compreensão dos processos de constituição de sentido pela linguagem, que variam em função das finalidades de cada jogo. No caso dos jogos característicos das ciências empíricas, os cientistas se interessam por encontrar as causas dos fenômenos que investigam, produzindo, assim, novos saberes, enquanto que as condições de sentido para estes mesmos saberes são razões pressupostas no interior de seus jogos de linguagem, que não se confundem com as causas.

${ }^{8}$ Cf. < http://www.incor.usp.br/conteudo-medico/decourt/semmelweis.html>
} 
Essa situação era um enigma para o corpo médico do hospital, porque, fora deste, o tifo espalhava-se cada vez mais. Até que, num dia, ao entrar no hospital e desviar-se de um tifoso moribundo caído na porta, C. Nicolle atinou com a explicação: o tifo detinha-se na porta do hospital porque, ao ingressar nele, os tifosos eram despidos, lavados, barbeados e tosados. Nessas condições, “o agente de contágio era, pois, algo alheio a ele [o doente], porém que levava sobre si mesmo, em sua roupa, sobre sua pele. Somente podia ser o piolho. Era o piolho" (AZANHA, 1992, p. 150)

Tanto Semmelweis como Nicolle eram pesquisadores renomados e experientes, com uma formação próxima de outros colegas de sua época, e, no entanto, os fatos casuais observados por eles foram ignorados não só pelos leigos, como também por seus colegas médicos, que vivenciavam cotidianamente as mesmas situações e detinham praticamente o mesmo conhecimento. Assim, algo mais parece ter ocorrido para que para aqueles dois médicos tenham observado indícios reveladores de um todo que transcendia o fato ocasional.

Segundo Azanha, na imaginação popular e mesmo na dos cientistas, esses episódios e outros análogos são frequentemente atribuídos à confluência de fatores aleatórios aos quais não falta a "sorte" do investigador, mas observa que, embora esta imagem não seja totalmente falsa, talvez fosse conveniente levar em conta também que "[...] o papel do acaso nessas descobertas fica determinado pela presença de outras condições não casuais", como por exemplo, é indispensável que haja um "observador teoricamente sensibilizado", pois só para um "olho clínico", um fato vem a ser estratégico (AZANHA, 1992, p. 150-152). Em outras palavras, não só nestes casos mencionados acima, como também em vários outros episódios da história da ciência, identificar um fato como sendo o ponto de partida para um conhecimento mais amplo da realidade exige uma perspicácia do investigador que envolve não apenas uma subjetividade privilegiada como também outras formas de inferência para além da dedução e da indução. Ainda segundo Azanha (1992), estas duas formas mais tradicionais do pensamento científico não bastam, pois não inovam. Lembra-nos que para o filósofo, lógico e linguista Charles Sanders Peirce haveria ainda outra forma de raciocínio, denominado por ele de abdução, que "simplesmente sugere que alguma coisa pode ser", raciocínio que poderia ser sintetizado através do seguinte esquema:

$$
\begin{aligned}
& \text { Um fato surpreendente, C, é observado; } \\
& \text { Mas se A fosse verdadeiro, C seria natural, } \\
& \text { Donde, há razão para suspeitar-se que A é verdadeiro. } \\
& \text { (Apud Azanha, 1992, p. 155) }
\end{aligned}
$$

Teria sido, então, esta forma de raciocínio que teria levado, nos dois casos apresentados acima, às descobertas das causas da doença puerperal e do tifo exantemático? Poderíamos argumentar que, no primeiro caso, o fato surpreendente para Semmelweis teria sido o de que os partos realizados em casa eram bem mais seguros do que dentro dos hospitais, dado que neles o risco de se ter a febre puerperal era muito maior; e para Nicolle, inversamente, o fato de que não havia contágio do tifo dentro dos hospitais, sendo estes um lugar absolutamente muito mais seguro do que nas ruas onde o tifo se alastrava. A 
imaginação de cada um dos médicos aliada às suas respectivas formações teóricas parecem ter sido os ingredientes essenciais para que, no caso de Semmelweis, um novo aspecto tenha sido percebido por ele ao comparar os sintomas apresentados por seu colega (após um ferimento por instrumento cortante em uma aula de autópsia) com os das parturientes que eram acometidas pela febre puerperal, e, por analogia, ter concluído que todos haviam sido infectados pela mesma razão; e no caso de Nicolle, outras comparações teriam sido feitas para que tenha sido capaz de elaborar a hipótese de que o piolho era o agente transmissor do tifo. Assim, o raciocínio da abdução estaria presente, em alguma medida, nestes casos (e em outros análogos), levando os dois pesquisadores a levantar hipóteses que não fariam sentido nos "jogos de linguagem" usuais, mas que se mostraram decisivas para a ampliação do conhecimento ou para uma explicação plausível de problemas que parecem insolúveis? .

Em uma terminologia wittgensteiniana, digamos que ambos médicos instauraram novas regras de sentido, por terem sido capazes de ver no acaso um novo aspecto da situação problemática então vivenciada pela coletividade. Assim, não foi o acaso "em si" que os levou a uma nova compreensão dos problemas enfrentados naqueles contextos históricos, mas as novas conexões de sentido por eles estabelecidas, como que "sopradas" pelo acaso. Portanto, os fatos surpreendentes a serem explicados nestas duas descobertas científicas puderam ser desvendados a partir de fatos triviais, ignorados pelos colegas médicos de Semmelweis e de Nicolle. Ocorrências banais e corriqueiras adquiriram novos sentidos ao serem vistos por um novo ponto de vista teórico, ou seja, os dois médicos foram capazes de ver determinados aspectos de situações cotidianas como pertencentes a outros jogos de linguagem, inventando novas regras enquanto "jogavam" (as we go along). Regras que, entretanto, enfrentaram grande resistência por boa parte da comunidade médica até serem finalmente aceitas.

Vejamos então, um pouco mais de perto, como se dá este entrelaçamento de fatos empíricos fortuitos e banais com o estabelecimento de novas regras linguísticas, que por sua vez, tornam-se condições para atribuição de novos sentidos a estes fatos, até então, casuais, esclarecendo-se, assim, o que nos parecia surpreendente e enigmático.

\section{O acaso na formação humana}

Ao olharmos para a linguagem como este conjunto aberto de diferentes jogos de linguagem, comunicando-se entre si de diversas formas, e cujas regras se alteram com o tempo, o conceito de saber também adquire novas conotações. Dependendo do jogo de linguagem em que este conceito é aplicado, podemos estar nos referindo a um saber prático, como saber fazer algo; como também a um saber que, um conhecimento das próprias regras do jogo. Este último saber pode ter um uso descritivo, como ocorre, por exemplo, nas ciências empíricas. Como vimos nos exemplos dados acima, as hipóteses formuladas pelos médicos são postas à prova recorrendo-se aos fatos do mundo para confirmá-las e, assim, explicar o fenômeno que está sendo investigado. Enquanto que há saberes, segundo

\footnotetext{
${ }^{9} \mathrm{Na}$ esteira das reflexões de Peirce e de sua formulação lógica de uma forma de raciocínio relativamente frequente na história da ciência, pensadores das áreas das ciências humanas se debruçaram sobre formas análogas de investigação, retomando conceitos como os de insight, serendipity, indícios paradigmáticos, fato social total, entre outros, para explicar a possibilidade de se transitar de um fato particular para uma compreensão mais globalizante no âmbito das ciências humanas (AZANHA, 1992).
} 
Wittgenstein, que não são postos à prova, como vemos em enunciados que têm uma função normativa, e que desempenham o papel de regras, enunciados que se tornam "o substrato de toda minha investigação e asserções", como observa Wittgenstein em seus últimos escritos:

Em geral considero como verdadeiro o que se encontra em livros escolares de geografia, por exemplo. Por quê? Eu digo: todos esses fatos foram confirmados centenas de vezes. Mas como eu sei disso? Qual é a evidência que tenho para isso? Eu tenho uma imagem do mundo [Weltbild]. É verdadeira ou falsa? Acima de tudo, é o substrato de toda minha investigação e asserções. As proposições que a descrevem não são todas igualmente sujeitas a prova. (DC, \$162)

Os fatos, por exemplo, de que o mundo existe, rios e montanhas existem, etc., não são questionados pela criança que estuda geografia na escola. São incorporados por ela tacitamente, e, na maior parte das vezes, nem chegam a ser explicitados. Um professor não diz a seus alunos que "tal rio existe". Apenas ensina que o rio recebe vários afluentes, tem tal extensão e se situa em determinada região. A proposição de que "o rio existe" não têm uma função descritiva, não vamos a campo verificar sua existência, ou a existência do mundo, ou se existem montanhas. Em outras palavras, os enunciados de existência não são verdadeiros ou falsos, são apenas condição de sentido para que possamos descrever determinadas montanhas, ou afirmar que a Terra é redonda (e não plana), constituindo-se, assim, dentro de cada um, uma imagem de mundo que é compartilhada pela comunidade na qual vivemos, "[...] a qual está ligada conjuntamente pela ciência e pela educação" (DC, $\$ 298)$

Analogamente aos enunciados de existência, várias outras certezas vão sendo constituídas a partir dos usos que fazemos das palavras e de nossas expressões linguísticas, e passam a desempenhar o papel de regras, indicativas ou normativas, em função do jogo de linguagem do qual fazem parte. Este saber tácito é, portanto, de natureza diferente da dos saberes empíricos, estes sim, verificáveis direta ou indiretamente. Em uma terminologia wittgensteiniana, estas certezas adquiridas tacitamente constituem uma gramática que carregamos dentro de nós, desempenhando o papel de fundamento dos sentidos que atribuímos aos fatos do mundo, um fundamento que está ancorado em nossas formas de vida, ou seja, em nossos hábitos, costumes e instituições, e que se torna condição de possibilidade para o conhecimento empírico.

No entanto, a multiplicidade de funções da linguagem tem sido desconsiderada em nossas práticas formativas, onde ainda é predominante um modelo referencial da linguagem, a saber, que toda palavra deve designar "algo", que seria o fundamento último de sua significação, a ser localizado em um domínio extralinguístico. Em outros termos, como se o significado de uma palavra ou de uma expressão linguística fosse sua referência situada no mundo empírico, ou ainda, em um mundo ideal e/ou mental. Ou ainda, como se houvesse uma ligação direta entre a palavra e objeto à que ela se refere ${ }^{10}$. Em contraposição

\footnotetext{
${ }_{10}$ No campo da filosofia, Wittgenstein faz a terapia filosófica deste modelo, mostrando que, ao se reduzir a linguagem a um uso exclusivamente referencial, somos levados a diversas confusões filosóficas de natureza conceitual, em particular no caso de epistemologias que procuram fundamentos últimos em domínios extralinguísticos. Penso que as mesmas confusões ocorrem em nossas práticas educacionais, na medida em que toda teoria da aprendizagem se apoia em uma teoria do conhecimento, "transportando-se", assim, os paradoxos e enigmas filosóficos para o campo educacional.
} 
ao modelo referencial da linguagem, Wittgenstein nos mostra que não há um fundamento último e absoluto que perpasse as diferentes aplicações de uma mesma palavra, observando que seus diferentes usos se relacionam através de "semelhanças de família", outro conceito basilar na segunda fase de seu pensamento. Dito de outro modo, a palavra que expressa um determinado conceito pode ser aplicada seguindo-se diversas regras, que mantêm entre si semelhanças em maior ou menor grau, o que possibilita que se atribua diferentes sentidos a ela à medida em que transitamos dentro de um mesmo jogo de linguagem, como também entre jogos de linguagem diferentes (IF SS 66-67).

A significação de um conceito decorre, portanto, deste conjunto aberto de sentidos que atribuímos à palavra que expressa o conceito em questão. Ao transpormos esta concepção pragmática de linguagem para o contexto educacional, parece-nos que aprender/compreender o significado de um novo conceito também pressupõe o domínio de diferentes técnicas e um certo número de exemplos de sua aplicação. Só assim um estudante será capaz de aplicá-lo em diversas situações, diferentes das que foram apresentadas inicialmente por seu professor. Segundo nosso filósofo: "É evidente que a gramática da palavra "saber" goza de estreito parentesco com a gramática das palavras "poder", "ser capaz". Mas também com a gramática da palavra "compreender". ('Dominar' uma técnica)." (IF, $\$ 150$, grifo meu)

Desta perspectiva pragmática da linguagem, saber algo, portanto, pressupõe ser capaz de seguir uma ou mais regras que fazem parte da gramática dos conceitos em questão, o que envolve o aprendizado de diversas técnicas linguísticas e modos de agir, de natureza convencional. Estas técnicas não são extraídas da observação ou experimentação empírica, mas sim inventadas pelo homem. O próprio jogo de linguagem da denominação, em que atribuímos nomes a determinados objetos, já é permeado por diversas técnicas linguísticas. Por exemplo, ao apontarmos para um objeto qualquer em resposta à pergunta sobre o significado de uma determinada palavra ("o que é caneta? ”), o gesto ostensivo terá a função de estabelecer uma ligação de sentido entre o som empírico da palavra "caneta" e o objeto apontado. Mas a diferença da concepção referencial da linguagem, o objeto apontado não é o significado da palavra "caneta", mas apenas uma amostra do que é ser caneta. Esta amostra de caneta passa então a ter uma função paradigmática, diz o que é ser uma caneta. Outras amostras de caneta podem ser apresentadas até que o nosso interlocutor seja capaz, a partir de um certo momento, de olhar para uma caneta diferente de todas as anteriores e afirmar, por si só, de que se trata de uma caneta. Constitui-se aqui uma regra, dentre outras, que o outro aprendeu a seguir para aplicar a palavra"caneta", uma regra que fará parte da gramática do conceito de caneta: serve para escrever, tem uma determinada forma, sua tinta acaba a partir de um certo tempo de uso, etc. Analogamente, se uma criança, que ainda não aprendeu os nomes das cores, nos pergunta pelo nome da cor da caneta, novas técnicas são acionadas, como tabelas para cores, ou na falta delas, podemos recorrer a manchas de cores, fragmentos de tecidos coloridos, como amostras de nossa gramática das cores.

Assim, ao olharmos como de fato utilizamos as palavras de nossa linguagem, a concepção referencial da linguagem é relativizada. Não se pressupõe mais uma ligação direta entre a palavra e objeto à que ela se refere. Como vemos nos exemplos acima, esta relação é intermediada por diferentes técnicas, tais como, o gesto ostensivo, objetos que são incorporados pela linguagem como paradigmas para uso das palavras, tabelas, entre 
outros instrumentos linguísticos, estabelecendo-se, assim, relações internas de sentido; em oposição às relações externas de causa e efeito, características das ciências (MORENO, 2019). As regras que instauramos (expressas linguisticamente na forma de relações conceituais) tornam-se condições de sentido para a investigação de causas para os fenômenos empíricos do mundo interno ou externo.

Assim, as certezas de que "isto é uma caneta", que "vejo uma caneta azul", que "as sensações são privadas", ou a de que "não podemos ter acesso à mente do outro", etc., não descrevem nada do mundo externo ou interno, são enunciados que desempenham o papel de regras que aprendemos a seguir para atribuir sentido ao que observamos no outro e em nós mesmos. Não é relevante a minha sensação privada da cor da caneta que estou vendo agora, se vejo uma caneta azul ou verde, o que importa é se aprendi a seguir as regras dos conceitos de azul, verde, vermelho, entre outros, que fazem parte da nossa gramática das cores. Independentemente de minhas sensações privadas, eu mesma não saberia dizer o que estou percebendo se não tivesse o conceito de azul, vermelho, verde etc.. É o caráter público das regras que permite a comunicação e a produção de saberes no interior de uma forma de vida. Estas diferentes gramáticas que carregamos dentro de nós que nos permitem estabelecer relações entre o interno e o externo, atribuindo sentido ao que dizemos, sentimos e observamos em nós mesmos e nos outros. Em suma, concordamos nas formas de vida expressas na linguagem, no interior de nossos diferentes jogos de linguagem, não se trata de um acordo (empírico) de opiniões (IF, 241). E é partir destes acordos profundos que somos capazes de discernir entre o que é esperado, e o que se coloca como imprevisto ou casual.

\section{O acaso como condição para uma formação antidogmática}

O parágrafo 559 de DC mencionado acima, em que Wittgenstein ressalta a imprevisibilidade de nossos jogos de linguagens, é seguido pela seguinte afirmação: “[...] o conceito de saber está associado ao de jogo de linguagem” (DC \$560). Penso que esta afirmação ganha sentido a partir das considerações anteriores: somos treinados a agir de determinadas formas e acreditar em certezas que passamos a seguir cegamente (IF \219). Entretanto, isto não nos torna meros autômatos, pelo contrário, só podemos questionar ou duvidar a partir de sistemas de referência já firmemente estabelecidos. Ainda segundo o filósofo, a dúvida pressupõe certezas: "Com efeito, como é que uma criança pode duvidar imediatamente daquilo que lhe ensinam? Isso só pode significar que ela era incapaz de aprender certos tipos de jogos de linguagem” (DC \$283). Poderíamos, então, acrescentar: o imprevisível só é percebido como tal no interior de jogos que foram aprendidos.

Retomando os exemplos de Semmelweis e Nicolle, o acaso propiciou um novo aspecto da situação vivida por eles, não no sentido de algo que já estava lá esperando ser descoberto, uma essência oculta pré-existente ou uma verdade latente a ser potencializada. Mas no sentido de uma nova conexão de sentido ter sido estabelecida por eles, uma nova regra ter sido inventada. No caso de Semmelweis, a regra de que a higiene das mãos é essencial para a prevenção da febre puerperal, evitando-se, assim, a contaminação de bactérias encontradas nos cadáveres que eram dissecados e autopsiados pelos médicos, 
antes de atenderem as parturientes que se encontravam no mesmo hospital. Como até então não havia esta prática, este costume, este modo de agir comum como fundamento do saber médico em relação a esta doença (a febre puerperal), o "jogo" que era jogado continuou a padecer de uma inércia que só pôde ser rompida muito tempo depois, à medida que novas certezas passaram a ser incorporadas e/ou as regras vigentes foram modificadas no interior deste jogo.

Algo semelhante, poderíamos dizer, ocorreu no caso de Nicolle. Com a diferença de que a própria prática de se limpar os doentes e despi-los de sua roupa, por si, explicava o fato destes doentes não transmitirem o tifo, esta era a razão que justificava o fato da doença não se alastrar dentro do hospital (agia-se assim). O enigma da não contaminação dentro do hospital foi resolvido quando Nicolle foi capaz de ver um novo aspecto nesta prática, que passava desapercebido entre os demais médicos e pesquisadores, a saber, que o agente de contágio era algo externo aos doentes, presente em seus corpos e em suas roupas. O piolho era a causa da transmissão do tifo, enquanto que a justificativa para que o contágio não estivesse ocorrendo nos hospitais assentava-se em uma prática, em um modo de agir. Assim, ambos os médicos foram capazes de ver um novo aspecto a partir de fatos corriqueiros, e não surpreendentes, imaginando outras ligações de sentido como fundamentos de suas respectivas hipóteses, conexões que passaram a ser incorporadas às gramáticas dos conceitos de febre puerperal e de tifo, dissolvendo-se, assim, os enigmas por eles enfrentados e produzindo novos saberes. Em suma, tendo como pano de fundo a regularidade de nossos jogos de linguagem, compartilhados por uma comunidade no tempo e no espaço, Semmelweis e Nicolle foram capazes de ver novos aspectos de situações cotidianas como pertencentes a outros jogos de linguagem, inventando e/ou modificando regras, enquanto "jogavam".

De modo mais geral, na formação inicial do ser humano, também passamos por um treinamento inicial que possibilita a nossa inserção nos mais diferentes jogos da linguagem - tanto os jogos de linguagem das ciências como os da nossa vida cotidiana -, formando-se, assim, o indivíduo em uma coletividade que compartilha modos de agir, produzindo acordos que se dão na linguagem, na medida em que aprendemos gradativamente a seguir as regras que fazem parte da gramática de nossos conceitos. Tratase, portanto, de uma formação, a saber, somos introduzidos a formas linguísticas que estão radicadas, por sua vez, em modos de agir coletivos. Aprendemos determinados conceitos e expressões linguísticas sem aprender, necessariamente, suas eventuais referências, basta termos sido apresentados a um certo número de usos destes conceitos ou expressões da linguagem, em situações efetivas de aplicação das palavras que os expressam.

As confusões surgem quando privilegiamos um único uso de um determinado conceito, pertencente a um determinado jogo de linguagem, em detrimento de outros usos possíveis. Nos jogos de linguagem das ciências há vários episódios em que este uso exclusivista ocorre, como vimos nos casos abordados acima. A aplicação dogmática de um conceito, porém, também ocorre nas práticas escolares, quando o professor não leva em consideração usos prévios de conceitos já utilizados pelos alunos em outros jogos de linguagem, e impõe uma única definição (regra) como sendo a correta para aplicá-los, como se houvesse um fundamento absoluto e último da significação do conceito em questão, que supostamente abrangeria todos os possíveis casos de sua aplicação. Estes usos considerados necessários de um conceito são denominados de imagens por Wittgenstein, 
que se tornam dogmáticas ao se pressupor um fundamento extralinguístico para elas. No entanto, “[...] as imagens não são descrições definitivas do mundo, uma vez que este é decantado e modelado por nossas ações imprevisíveis e por nossos conceitos necessários, mas sempre provisórios assentados que estão sobre essas ações” (MORENO, 1995, p. 43). Em outras palavras, estas imagens poderiam ser outras, em outras formas de vida. Assim, ao se desconsiderar a multiplicidade de usos de nossos conceitos e expressões linguísticas e, fundamentalmente, a imprevisibilidade de nossas ações, diversos equívocos surgem, não apenas nas práticas científicas, como também nas práticas pedagógicas (GOTTSCHALK, 2018, 2020), impedindo uma formação humana mais crítica e reflexiva.

Outra fonte de confusão que reverbera nas práticas pedagógicas repousa na crença de que todos os enunciados linguísticos teriam uma função descritiva, desconsiderando-se outras afirmações que desempenham uma função expressiva, ou na terminologia wittgensteiniana, proposições gramaticais que têm um uso normativo ou indicativo, como é o caso de nossas certezas mais fundamentais. Como vimos, estas não descrevem nada do mundo, são apenas condições para eventuais descrições. Confundir estes diferentes usos nas práticas de ensino tem como uma de suas implicações esperar que o aluno seja capaz de descobrir por si só a significação de determinados enunciados, a partir de "situações de aprendizado", onde o professor deveria desempenhar apenas o papel de facilitador ou mero mediador de tais descobertas. No entanto, descobertas empíricas pressupõem novas ligações de sentido, ligações que são de natureza convencional e que, como vimos, nem sempre são aceitas facilmente. Esperar que o aluno por si só estabeleça novas regras como se estas fossem passíveis de serem extraídas da observação empírica é condená-lo a não aprender.

Embora a epígrafe de Platão, no início deste texto, afirme que "o que sucede por casualidade não é efeito de direção humana”, um fato só é fato no interior de um jogo de linguagem. Consequentemente, o que consideramos um acaso, ou um fato inesperado, só o é no interior de um jogo de linguagem. Somos nós, como seres linguísticos, que inventamos os conceitos de acaso, casualidade, imprevisibilidade, absurdo, fugaz, e tantos outros, em oposição a conceitos cujas gramáticas são constituídas por regras com um certo grau de vagueza, o que nos permite antecipar determinados acontecimentos, atribuindo sentido a eles e delimitando (provisoriamente) o nosso modo de pensar; ao mesmo tempo em que é também a vagueza das regras que possibilita a passagem de um jogo para o outro, incorporando fatos casuais e ampliando, assim, o espectro do significado de nossos conceitos.

Enfim, o acaso que nos possibilita ver novos aspectos no que nos parece absurdo e fugaz é uma das condições sine qua non para continuarmos a sermos humanos, e não máquinas. $\mathrm{O}$ acaso nos incita a repensar nossas regras, a inventarmos novas normas de sentido, ampliando-se e reformulando-se, assim, os nossos saberes. O acaso e seus congêneres, enfim, podem ser vistos como antídotos contra o dogmatismo, tanto nos jogos de linguagem das ciências como na formação humana. Parafraseando a artista Frida Kahlo, o que faríamos sem o acaso? 


\section{Referências}

AZANHA, J. M. P. Uma ideia de pesquisa educacional. São Paulo: Edusp, 1992.

GOTTSCHALK, C. M. C. Teaching critical thinking: The struggle against dogmatism. Educational Philosophy and Theory, v. 50, n. 5, p. 469-477, 2018.

Published online: 08 Jun 2016. Disponível em:

< https://www.tandfonline.com/doi/ref/10.1080/00131857.2016.1168731> Acesso em 09 jan. 2021

O colapso do sentido em tempos sombrios, um retorno à barbárie? Convenit Internacional, n. 33, maio/ago, p. 1-12, 2020. Disponível em:

$<$ https://www.hottopos.comconvenit33index.htm> Acesso em 09 jan. 2021

MORENO, A. R. Wittgenstein através das imagens. Campinas: Editora da Unicamp, 1995.

. Pragmatique de la relation/propriété interne : l'aspect. Revue de

Métaphysique et de Morale, n. 4, octobre-décembre, p. 363-379, 2019.

PLATÃO. Mênon. Tradução de Maura Iglésias. Rio de Janeiro: Ed. PUC-Rio; Loyola, 2001.

WITTGENSTEIN, L. On Certainty. Oxford: Basil Blackwell, 1979.

Fichas (Zettel). Lisboa: Edição 70, 1989.

Investigações Filosóficas. Petrópolis: Editora Vozes, 1996. 